August 2005

\title{
Suicidal bus bombing of French nationals in Pakistan: physical injuries and management of survivors
}

\author{
Hasnain Zafar \\ Aga Khan University, hasnain.zafar@aku.edu \\ Rifat Rehmani \\ Aga Khan University, rifat.rehmani@aku.edu \\ Tabish Chawla \\ Aga Khan University, tabish.chawla@aku.edu \\ masood umer \\ Aga Khan University, masood.umer@aku.edu \\ Mohsin-e-Azam \\ Aga Khan University
}

Follow this and additional works at: http://ecommons.aku.edu/pakistan_fhs_mc_surg_surg

Part of the Orthopedics Commons

\section{Recommended Citation}

Zafar, H., Rehmani, R., Chawla, T., umer, m., Mohsin-e-Azam, . (2005). Suicidal bus bombing of French nationals in Pakistan: physical injuries and management of survivors. Eur J Emerg Med., 12(4), 163-167.

Available at: http://ecommons.aku.edu/pakistan_fhs_mc_surg_surg/223 


\section{Suicidal bus bombing of French Nationals in Pakistan: physical injuries and management of survivors Hasnain Zafar ${ }^{a}$, Rifat Rehmani ${ }^{b}$, Tabish Chawla ${ }^{a}$, Masood Umer ${ }^{a}$ and Mohsin-e-Azam ${ }^{a}$}

\begin{abstract}
Background: Suicidal bombing is particularly devastating and an increasingly common form of terrorist violence. In this paper, we present an epidemiologic description of the physical injuries of patients who survived the suicidal bombing attack in the context of the limited medical resources of a developing nation.
\end{abstract}

Methods: The management of individual patients was reviewed from a preprinted trauma form. Information on the nature of injuries, operative management and hospital course was recorded and data analyzed using the Trauma Registry.

Results: Twelve survivors out of 36 bomb blast victims brought to the Aga Khan University Hospital were transferred from primary receiving hospitals. The average number of injuries per patient was eight. The mean Injury Severity Score was 10.8. The majority of patients had secondary and tertiary blast injuries. Most of the survivors had calcaneal injuries; these have not been reported in the literature in similar terrorist attacks. Twelve operative interventions were undertaken. All of the 12 patients were stabilized and evacuated within $24 \mathrm{~h}$ of admission.

Conclusions: All of the 12 patients transferred to the Aga Khan University Hospital survived. Unlike the reported injuries, calcaneal fractures were most commonly encountered in the survivors. European Journal of Emergency Medicine 12:163-167 (c) 2005 Lippincott Williams \& Wilkins.

European Journal of Emergency Medicine 2005, 12:163-167

Keywords: calcaneal fractures, suicidal bombing, trauma

aDepartment of Surgery, The Aga Khan University Hospital, Karachi, Pakistan and ${ }^{b}$ Section of Emergency Medicine, The Aga Khan University Hospital, Karachi, Pakistan.

Correspondence and requests for reprints to Rifat Rehmani FRCSEd (A\&E), Assistant Professor, Section of Emergency Medicine, The Aga Khan University Hospital, P.O. Box 3500, Karachi 74800, Pakistan.

Tel: + 9221 48591080; fax: +9221 4934294;

e-mail: rifat.rehmani@aku.edu

8 May 2002 at 7:45 a.m., a suicide bomber exploded his car next to a bus carrying French engineers working on the Agosta-90B Submarine in the southern district of Karachi. The explosion ripped the vehicle apart with debris scattered up to half a kilometer from the site of the bombing, leaving 13 dead.

\section{Study objectives}

The paper will describe the nature of the injuries of patients involved in this bombing, their management and the interhospital transfers, and will highlight the difficulties of managing mass casualties in the setting of developing countries.

\section{Methods}

\section{Study site}

Karachi is a city of 13 million. Because an organized emergency medical services system does not exist in Pakistan, communication from the incident scene to the hospital is absent [12]. Trauma victims are carried or driven to the emergency department by bystanders or family members. Hospitals are never alerted as to when trauma patients may arrive, how many patients are involved or the severity of injuries. The lack of a field triage system makes the distribution of casualties a
Karachi is a port city of Pakistan and has been witness to many terrorist attacks on high profile western targets. On 
difficult and unorganized task. This distribution is usually determined by the distance to one of the three hospitals designated by the government to receive trauma patients. The ambulance is mostly a vehicle having a stretcher; drivers have no formal training [13]. Consequently, the initial management is initiated at the hospital.

The Aga Khan University Hospital (AKUH) is a private tertiary care hospital, with a commitment to provide trauma care [14]. Fifty percent of all trauma patients presenting to AKUH are transferred from governmentdesignated hospitals. The hospital has all the surgical specialties along with radiology, blood bank and 24-h availability of the operating room. It also has a multidisciplinary trauma team, with in-house attending or chief/senior residents in general surgery, anesthesia, neurosurgery, orthopedics and emergency medicine. All the members of the trauma team are formally trained in trauma management, and are primarily responsible for trauma care.

\section{Patient selection}

All patients transferred to AKUH from the public hospitals following disaster were included in the study. Information available on prehospital deaths and deaths in the primary receiving hospitals was insufficient to be evaluated or coded for injury severity score (ISS), and therefore these patients were excluded from the study.

\section{Data collection}

Data collected for all the patients included: age, sex, mechanism of injury, vital signs on arrival, injuries sustained and outcome. All patients had their initial assessment and treatment on the basis of the Advanced Trauma and Life Support [15] principles and documen- ted on a preprinted trauma form. The trauma form contains information necessary to calculate the Abbreviated Injury Scale (AIS-90) score. The region of principal injury was assigned as that anatomic region which had the highest AIS score. The AIS-90 score was used to calculate the ISS. Physiological information collected included systolic blood pressure, respiratory rate and Glasgow Coma Scale score. The physiological parameters on arrival in the emergency room were used to yield the Revised Trauma Score [16]. The data on the process of care was also recorded.

\section{Results}

A total of 36 people, including the French engineers, were injured. They were initially taken to the three designated hospitals; $13(36 \%)$ of the victims were dead on arrival. The rest (23) survived initially; out of these, 11(30.5) died in the primary receiving hospitals [17]. The remaining 12(33\%) survivors were transferred to AKUH. Table 1 lists the injuries sustained by them.

The victims started to arrive in the emergency room at AKUH about an hour following the bomb blast. The mean interval between injury and transfer to our hospital was 267 min (range 94-585 min). The victims were all male, with a mean age of 40.5 years, ranging between 30 and 50 years.

The mean respiratory rate at presentation was 23 (range 20-26) and the Glasgow Coma Score was 15. The mean systolic blood pressure was 126 (range 78-184). The mean revised trauma score on presentation was 7.467 (range 4.094-7.841).

Table 1 Most common injuries sustained by patients

\begin{tabular}{|c|c|c|}
\hline ISS & Principal injuries & Other injuries \\
\hline 10 & $\begin{array}{l}\text { Comminuted fracture of left olecranon process and radial neck, fracture of left } \\
\text { proximal fibula, bilateral calcaneal fractures with right subtalar subluxation }\end{array}$ & Multiple lacerations \\
\hline 5 & Bilateral intraarticular calcaneal fractures & Left tympanic membrane perforation, laceration of right external ear \\
\hline 6 & Bilateral open calcaneal fractures & $\begin{array}{c}\text { Closed fracture of talus, bilateral tympanic membrane perforation, multiple } \\
\text { lacerations }\end{array}$ \\
\hline 9 & Open intraarticular fracture of left medial malleolus & $\begin{array}{c}\text { Closed fracture of three ribs and left lung contusion, multiple lacerations and } \\
\text { abrasions, right tympanic membrane perforation }\end{array}$ \\
\hline 5 & Fracture of left medial malleolus and calcaneum & Bilateral tympanic membrane perforation, lacerations on face \\
\hline 17 & $\begin{array}{l}\text { Fracture of right iliac bone, fracture of right calcaneum, intraabdominal } \\
\text { shrapnel in right upper quadrant }\end{array}$ & $\begin{array}{l}\text { Dislocation of talonavicular joint, fracture body of L1, closed fracture of two } \\
\text { right ribs, multiple lacerations }\end{array}$ \\
\hline 11 & Comminuted intertrochantric fracture of left femur & $\begin{array}{c}\text { Fracture of lateral condyle of humerus, multiple lacerations and abrasions, } \\
\text { bilateral tympanic membrane perforation }\end{array}$ \\
\hline 6 & $\begin{array}{l}\text { Bilateral open ankle fractures, left distal tibia fibula intraarticular fracture, left } \\
\text { foot open fracture with dislocation at calcaneonavicular joint and mid tarsal } \\
\text { joint, right open intraarticular fracture of calcaneum with dislocation at subtalar } \\
\text { joint }\end{array}$ & Abdominal wound with glass, laceration on eyelids \\
\hline 5 & $\begin{array}{l}\text { Open fracture of right calcaneum and closed fracture of left calcaneum, } \\
\text { fracture of left fibula }\end{array}$ & Bilateral tympanic membrane perforation \\
\hline 14 & $\begin{array}{l}\text { Fracture of left talus and fifth metatarsal bone, fracture of right calcaneum, } \\
\text { cardiac contusion, bimalleolar fracture of left ankle }\end{array}$ & Left tympanic membrane perforation, multiple lacerations \\
\hline 5 & Bilateral closed calcaneal fractures & Facial lacerations, multiple abrasions \\
\hline 36 & $\begin{array}{c}\text { Splenic injury, left flail chest, open fracture of metacarpal bone, bilateral open } \\
\text { fracture of calcaneum }\end{array}$ & Facial lacerations, bilateral tympanic membrane perforation \\
\hline
\end{tabular}


All patients had multiple shrapnel lacerations and lower limb fractures; 11 out of 12 patients had fractures of the foot and ankle region, out of which seven had bilateral calcaneal fractures. Five calcaneal fractures were compound Grade III A [18]. Seven patients had associated fractures or fracture dislocations of adjacent articulating bones or distal tibia. Eight patients had confirmed tympanic membrane perforations. The mean number of injuries was 8 and the mean ISS was 10.8, ranging from 5 to 36 .

Two patients were considered to have severe injuries (ISS $>15$ ) and two had limb-threatening injuries. The patients were resuscitated and investigated in the emergency room. The mean stay in the emergency room was $163 \mathrm{~min}$ and the maximum stay was $294 \mathrm{~min}$.

\section{Individual patient management}

Three patients with highest ISS are described in detail.

\section{Case 1}

A 50-year-old diabetic, with an ISS of 36 , had the following injuries: (1) open bilateral calcaneal fractures, (2) fracture of the left first metacarpal, (3) left flail chest with hemothorax, (4) splenic injury, grade IV and (5) multiple facial lacerations.

His chest X-ray showed a left lower flail segment (8-11 ribs), and a computed tomographic scan of the abdomen revealed splenic injury, grade IV, with left hemothorax. Tube thoracostomy was done and the patient was admitted to intensive care. The surgery was delayed because of hyperkalemia; this was managed initially, followed by laporatomy and splenectomy. Also, the fractures were stabilized, severed tendons repaired, foreign bodies removed and the debridement of all the wounds was done. He received intravenous fluids, antibiotics and analgesia.

\section{Case 2}

A 39-year-old, with an ISS of 17, had the following injuries: (1) fracture of the right calcaneum with dislocation of talonavicular joint, (2) undisplaced right iliac fracture, (3) stable burst fracture of first lumbar vertebra and (4) multiple shrapnel injuries over the extremities and scalp.

A computed tomographic scan of the abdomen revealed intraabdominal shrapnel in the right upper quadrant, requiring laporatomy. The fractures and dislocations were reduced, foreign bodies removed and the debridement of all the wounds was done.

\section{Case 3}

A 40-year-old, with an ISS of 14, had the following injuries: (1) fracture of the left talus and fifth metatarsal,
(2) fracture of the right calcaneum, (3) left lower ribs fracture, (4) cardiac contusion, (5) tympanic membrane rupture and (6) bimalleolar fracture of the left ankle.

His electrocardiogram revealed sinus arrhythmia and raised creatinine phosphokinase suggesting blunt cardiac injuries; echo was normal. The fractures were reduced, and debridement was done.

\section{Evacuation of patients}

The 12 survivors were evacuated within $24 \mathrm{~h}$ of admission. The decision for evacuation was made by the French authorities.

\section{Discussion}

The high immediate death rate of $66 \%$ (24 dead out of 36 casualties) in this series compares closely with the outcome of the Beirut bombing of Americans, with 68\% immediate deaths [8]. The outcome of bombing in a closed building in Paris had an immediate death rate of 5\% (13 dead out of 268 patients) [19]. The high immediate rates are attributed to the magnitude of explosion, building collapse and indoor location of casualties. In the explosion at Karachi, building collapse was not a factor. The outcome is a function of the magnitude of blast force and location of victims in the confined space of a bus. However, we feel the poor outcome could have been improved by the immediate presence of surgical capability and established prehospital care.

Lack of organized prehospital care contributed significantly to the poor outcome. Lack of trained paramedics and record-keeping in our ambulances made it impossible to provide the victims with any medical care during transportation. Similarly, very little information is retrievable in the case of the remaining 13 who died in primary receiving hospitals, because of limited record-keeping at Government hospitals; also, on that day, the hospitals were overwhelmed because of the sudden influx of casualties and did not record even the routine aspects of care. Lack of communication between AKUH and the public sector hospitals made it difficult to ascertain the treatment received by these patients at those hospitals.

The survivors were transferred from primary receiving hospitals to the AKUH. In the French bombing case, the decision to transfer patients was made by the Pakistan Navy and French authorities and was conveyed to the hospital administration. Consequently, patients began to arrive in the hospital. The nature of the casualties and type of injuries was not communicated because of the lack of a central triage authority. Each patient was transferred with a small note, including the treatment given at the primary hospital. The physicians in the hospital got information of the incident and the victims 
from media channels such as $\mathrm{CNN}$ and $\mathrm{BBC}$ on the emergency room waiting-area television. The media channels provided a very valuable insight, to the physicians, into the mechanism of injuries and number of casualties. These media channels are invaluable in the setting of developing countries.

Injuries after bomb blasts have traditionally been divided into primary, secondary and tertiary injuries. Primary blast injury occurs as a direct effect of changes in atmospheric pressure caused by a blast wave. Most critical injuries are found among those immediately killed after terrorist bombing. Of the 12 patients admitted to the hospital, eight suffered perforated tympanic membranes; in five cases it was bilateral and in some, the status of the tympanic membranes could not be confirmed because of wax or blood in the external auditory meatus. This was the commonest primary blast injury. Apparently, no case of primary blast lung was reported among the survivors. Blast lung is a phenomenon occurring very early following exposure to the blast and is characterized by dyspnea and frothy bloodstained pulmonary exudates and frequently pnemothoraces. This finding is consistent with the previous studies $[2,6]$. No primary blast injury to bowel was seen in the survivors. Previous studies [20,21] have claimed that, while the proportion of primary blast injuries is relatively small among civilian victims of terrorism, most of the severe injuries are attributed to secondary blast effects, such as shrapnel wounds. Our results are consistent with these studies.

Secondary blast injuries occur when objects accelerated by the energy of the explosion strike a victim, causing either blunt or penetrating ballistic trauma. Tertiary blast injuries result from a victim's body being displaced by expanding gases and high winds; trauma then occurs from tumbling and impacting objects [22].

Most of the survivors suffered soft-tissue and musculoskeletal injuries; these were not life-threatening, except in three patients with ISS $>14$. The majority of patients seen at AKUH had secondary and tertiary blast injuries. Most of them had multiple small puncture wounds and abrasions. The injuries due to fragments of metal from the bomb itself and blast-driven debris and glass can cause a wide variety of injuries, determined by the size of the fragment and the site of the injury. The larger fragments caused serious fractures and loss of tissue.

The most common injuries found in our series are fracture or dislocation of the calcaneum and of the feet and anklebones. The injuries were mainly in the lower limbs probably because of the physical location of the bomb-laden car. Eyewitness accounts and police reports [17] confirm that the bomb was placed in a car, which hit the bus from the side and below; the bomber drove his car up to the bus and exploded the device; thus, the bomb exploded beside, and at a lower level than, the bus. The bus was, therefore, thrown up and away from its original position by the explosion. The blast wave thus probably originated from underneath the passengers, making their feet and ankles very vulnerable. Eleven out of our 12 patients had badly comminuted fractures of the foot and ankle region. Ten patients had calcaneal fractures, six of them bilateral. Of these 10 patients, seven had either an associated plafond or an ankle fracture, indicating the tremendous magnitude of the blast wave. Such a unique combination of predominantly calcaneal and ankle fractures has not been reported previously in similar incidents and is postulated by us to be the result of the lower position of the suicide bomber's vehicle than the bus.

At any given time, terrorist bombing can create a mass casualty situation, the successful management of which requires an understanding of the mechanism of injury. The increasing frequency of terrorist violence globally mandates a widespread awareness among civilian surgeons of 'war surgery rules', including treating a large number of persons with multiple contaminated wounds.

Analysis of the injuries and location and timeliness of treatment provided to the victims demonstrates a great need for improved prehospital facilities. More importantly, this bombing demonstrates the need to develop city-wide disaster plans according to the resources available in our country.

\section{References}

1 Wiener SL, Barrett J. Explosions and explosive device-related injuries. In Trauma Management for Civilian and Military Physicians. Philadelphia, Pennsylvania: Saunders; 1986. pp. 13-26.

2 Frykberg ER. Medical management of disasters and mass casualties from terrorist bombings: how can we cope? J Trauma 2002; 53 201-212.

3 Phillips YY, Zajtchuk JT. The management of primary blast injury. In: Bellamy RF, Zajtchuk R, editors. Conventional Warfare: Ballistic, Blast, and Burn Injuries. Washington, District of Columbia: Office of the Surgeon General of the US Army; 1991. pp. 295-335.

4 Mallonee S, Shariat S, Stennies G, Waxweiler R, Hogan D, Jordan F. Physical injuries and fatalities resulting from the Oklahoma City bombing. J Am Med Assoc 1996; 276:382-387.

5 Pyper PC, Graham WJ. Analysis of terrorist injuries treated at Craigavon Area Hospital, Northern Ireland, 1972-1980. Injury 1983; 14: 332-338.

6 Hadden WA, Rutherford WH, Merrett JD. The injuries of terrorist bombing: a study of 1532 consecutive patients. Br J Surg 1978; 65:525-531.

7 Waterworth TA, Carr MJ. Surgery of violence: report on injuries sustained by patients treated at the Birmingham General Hospital following the recent bomb explosions. Brit Med J 1975; 2:25-27.

8 Frykberg ER, Tepas JJ, Alexander RH. The 1983 Beirut Airport terrorist bombing: injury patterns and implications for disaster management. Am Surg 1989; 55:134-141.

9 Arnold JL, Halpern P, Tsai M, Smithline H. Mass casualty terrorist bombing: a comparison of outcomes by bombing type. Ann Emerg Med 2004; 43: 263-273.

10 Peleg K, Daniel LA, Stein M, Michaelson M, Kluger Y, Simon D. Gunshot and explosion injuries. Characteristics, outcomes, and 
implications for care of terror-related injuries in Israel. Ann Surg 2004; 239: 311-318.

11 Kluger Y. Bomb explosions in acts of terrorism - detonation, wound ballistics, triage and medical concerns. Isr Med Assoc J 2003; 5:235-240 (www.ima.org.il/imaj/ar03ap-1.pdf).

12 Raftery KA. Emergency medicine in southern Pakistan. Ann Emerg Med 1996; 27:79-83.

13 Mehdi IJ. Emergency medicine in Pakistan. Ann Emerg Med 1996; 27: 84-88.

14 Zafar H, Rehmani R, Raja AJ. Registry based trauma outcome: perspective of a developing country. Emerg Med J 2002; 19:391-394.

15 American College of Surgeons Committee on Trauma. Advanced Trauma Life Support for doctors. 6th edn. Chicago (IL): American College of Surgeons; 1997.
16 Rehmani R, Zafar H, Hoda Q, Azami R, Raja AJ, editors. Trauma Manual. Karachi: Royal Book Company; 2003.

17 Shabir A, Hassan SR. Suicide bombing leaves 14 dead: explosive-laden car blows up near bus outside hotel. Dawn 9 May 2002; 1.

18 Gustilo RB, Merkow RL, Templeman D. The management of open fractures. J Bone jt Surg Am 1990; 72:299-304.

19 Rignault DP, Deligny MC. The 1986 terrorist bombing experience in Paris. Ann Surg 1998; 209:368-373.

20 Mellor SG. The pathogenesis of blast injury and its management. $\mathrm{Br} J \mathrm{Hosp}$ Med 1988; 39:536-539.

21 Cooper GJ, Maynard RL, Cross NL, Hill JF. Casualties from terrorist bombings. J Trauma 1983; 23:955-967.

22 Wightman JM, Gladish SL. Explosions and blast injuries. Ann Emerg Med 2001; 37:664-678. 